\title{
A taxa de disponibilidade para o parto: outra violência obstétrica?
}

\author{
Jéssica Santos de Almeida*, Daiany Santos de Almeida da Silva**, Zaida Aurora Sperli Geraldes Soler***
}

Via de regra a violência obstétrica no Brasil está relacionada à realização de cesarianas por motivos ilegítimos, à omissão de informações no transcorrer do ciclo gravídico-puerperal, enfim, ao desrespeito pelos sentimentos e necessidades das mulheres e famílias. Atualmente, as consumidoras de serviços de obstetrícia têm se queixado de cobrança extra pelo obstetra de sua escolha, para atendimento diferenciado no parto.

De acordo com a pesquisa divulgada em 2010, pela Fundação Perseu Abramo, uma em cada quatro mulheres sofre algum tipo de violência durante o parto [1]. Ainda, das denuncias registradas entre janeiro de 1996 a janeiro de 2002 junto ao Conselho Regional de Medicina de São Paulo (CREMESP), a obstetrícia é a especialidade médica com maior número de ocorrência de infraçóes [2].

A questão da cobrança pela disponibilidade obstétrica no parto é um assunto complexo e sua análise envolve consumidores, prestadores, planos de saúde, judiciário e órgãos de defesa do consumidor. A única certeza é que a gestante não deve ser responsabilizada ou prejudicada por falha na assistência. A taxa da disponibilidade obstétrica varia muito, entre $\mathrm{R} \$ 1.500,00$ a $\mathrm{R} \$ 5.000,00$ (mil e quinhentos reais a cinco mil reais) [3], valor que é cobrado integralmente da gestante que deseje ser assistida pelo médico de sua confiança, após assinatura de contrato particular entre as partes.
São vários olhares para tal situação:

- a cobrança da taxa de disponibilidade obstétrica no Sistema Único de Saúde (SUS): é inadmissível em qualquer circunstância, como previsto na Constituição Federal [3]. As ações e serviços de saúde que integram o SUS devem seguir fundamentalmente os princípios de universalidade, integralidade, preservação da autonomia, igualdade da assistência e direito à informação. Cobranças a usuários do SUS são consideradas improbidade administrativa, inadequação ao padrão ético e moral e corrupçáo passiva.

- a cobrança da taxa de disponibilidade obstétrica a gestante conveniada a operadora de plano de saúde depende do contrato, na verificação dos procedimentos cobertos pela operadora. A Agência Nacional de Saúde Suplementar (ANS) responsável por regular os planos de saúde no Brasil [4] recentemente pediu pareceres ao Conselho Federal de Medicina (CFM) e à Fundação de Proteção e Defesa do Consumidor (PROCON-SP) a respeito da taxa de disponibilidade obstétrica.

- a resolução do Conselho Federal de Medicina n¹834/2008 define que a disponibilidade médica de sobreaviso deve ser remunerada de forma justa, destacando-se que essa resoluçáo trata de contrato entre o médico e a instituição de saúde, não com o consumidor. Na ementa do parecer sobre co-

*Acadêmica de Enfermagem da Faculdade de Medicina de São José do Rio Preto (FAMERP), **Advogada, Graduada em Direito pela Faculdade Karing Bazarian de Itapetininga/SP, ***Obstetriz, Enfermeira, Livre-Docente em Enfermagem FAMERP (área Enfermagem Obstétrica), organizadora e coordenadora dos Cursos de Especialização em Enfermagem Obstétrica na FAMERP, docente e orientadora da graduação e pós-graduação Lato Sensu e Stricto Sensu da FAMERP, coordenadora geral da pós-graduação stricto sensu em Enfermagem - CAPES - Mestrado Acadêmico da FAMERP 
brança de disponibilidade médica em obstetrícia, o CFM expressa ser “(...) ético e não configura dupla cobrança o pagamento de honorário pela gestante referente ao acompanhamento presencial do trabalho de parto, desde que o obstetra não esteja de plantão e que este procedimento seja acordado com a gestante na primeira consulta" [5].

- a Fundação PROCON-SP [6] apresenta posição contrária, considerando "(...) a segmentação dos serviços de saúde, qual seja, a prestação do serviço de pré-natal dissociada da prestação do serviço de parto, é prejudicial ao consumidor afrontando inclusive o Princípio da Dignidade da Pessoa Humana.". Ainda, "considerando que a operadora do plano de assistência à saúde é responsável pelo repasse do pagamento dos honorários, (...) os honorários pela disponibilidade do profissional à gestante caracteriza a duplicidade da cobrança, ação esta proibida pelo Código de Ética Médico [2].

Ante tais consideraçóes, a Agência Nacional de Saúde Suplementar (ANS) considera que se a disponibilidade obstétrica for cobrada deve se alterar o contrato entre o beneficiário e a operadora, já que, na maioria dos contratos, os médicos conveniados devem realizar todos os procedimentos da gestação, ou seja, pré-natal, parto e puerpério e as operadoras de saúde podem ser multadas caso um médico conveniado cobre a taxa de disponibilidade obstétrica. A única situação que não existe impedimento jurídico para que o profissional cobre os honorários da sua disponibilidade é quando o atendimento é realizado totalmente em clínica particular.

Em recente divulgação na página da ANS - junho de 2014 - ficou reiterado que se no contrato esse procedimento está previsto, uma consumidora de plano hospitalar com obstetrícia tem o direito garantido de que os honorários médicos referentes a parto normal ou por cesárea serão em sua totalidade cobertos pela operadora [7].

\section{Referências}

1. Balogh G. Mulheres denunciam violência obstétrica: saiba se você foi vítima. [citado 2014 Jun 2]. Disponível em URL: http://maternar.blogfolha. uol.com.br/2014/03/12/mulheres-denunciam-violencia-obstetrica-saiba-se-voce-foi-vitima/

2. Rosas CF. Cadernos Cremesp. Ética em ginecologia e obstetrícia. In: Aspectos das denuncias, processos disciplinares e das principais infraçóes éticas de tocoginecologistas. 2a ed. São Paulo: Conselho Regional de Medicina do Estado de São Paulo; 2002. $141 \mathrm{p}$.

3. Lei n8080/90- Capitulo II: Princípios e diretrizes do SUS. Brasília: Diário Oficial da União; 1990.

4. 4. Resolução CFM no $1.834 / 2008$ (Publicada no D.O.U. de 14 de março de 2008, Seção I, pg. 195) Art 1 e 2. Brasília: Diário Oficial da União; 2008.

5. Processo consulta CFM no55/12 - Parecer CFM no39/12. [citado 2014 Mai 24]. Disponível em: URL: http://www.portalmedico.org.br/pareceres/ CFM/2012/39_2012.pdf

6. Parecer do Conselho Federal de Medicina no 39/12 consideraçóes da Fundação de Proteção e Defesa do Consumidor (PROCON). [citado 2014 Mai 24]. Disponível em: URL: http://www.ans.gov.br/ images/stories/noticias/posic_procon_gt_disponibilidade_reuniao1.pdf

7. ANS vai multar planos de saúde caso médico cobre adicional por parto. [citado 2014 Abr 11]. Disponível em URL: http://veja.abril.com.br/noticia/saude/ans-vai-multar-planos-de-saude-caso-medico-cobre-adicional-por-parto.

\section{Aviso ao assinante}

A Atlântica Editora lançou sua primeira revista científica Fisioterapia Brasil há 16 anos, e que se tornou referência no meio profissional. No decorrer dos anos seguiram mais seis revistas científicas. Apesar do reconhecimento acadêmico e profissional, tivemos algumas dificuldades durante esses anos, motivadas pelo aumento dos custos de produçáo gráfica, dos envios postais, do custo de participaçáo em congressos e eventos, bem como a ausência total de incentivo fiscal e dos correios, ao contrário de que se passa em outros países, onde a edição e a divulgaçáo científica são altamente favorecidas.

Em razão de mudanças e de reorganizaçáo na direçáo da Editora, alteramos o ritmo de publicaçáo de algumas revistas para colocar as ediçóes em dia. Isso náo muda a vigência de sua assinatura ora contratada, que inclui sempre 6 a 12 ediçóes até o término de seu contrato

Continuaremos regularmente com nossas publicaçôes, mantendo nossa qualidade editorial e científica.

Aproveitamos para agradecer a compreensão de todos os nossos autores, assinantes e leitores. 